\title{
Advanced Guidance and Control Methods for Reusable Launch Vehicles: Test Results \\ Draft
}

John M. Hanson ${ }^{1}$, Robert E. Jones ${ }^{2}$, Don R. Krupp ${ }^{1}$

\begin{abstract}
There are a number of approaches to advanced guidance and control (AG\&C) that have the potential for achieving the goals of significantly increasing reusable launch vehicle (RLV) safety/reliability and reducing the cost. In this paper, we examine some of these methods and compare the results. We briefly introduce the various methods under test, list the test cases used to demonstrate that the desired results are achieved, show an automated test scoring method that greatly reduces the evaluation effort required, and display results of the tests. Results are shown for the algorithms that have entered testing so far.
\end{abstract}

\section{Introduction}

Advanced guidance and control has a significant potential to increase the safety of future reusable launch vehicles, as well as to reduce the cost of performing guidance and control analysis, both in the design and in the operational phases. This potential has been documented elsewhere (Ref. 1). The Advanced Guidance and Control Project, supported by the NASA X-33 Program Office, had as its purpose to develop and test some of the potential methods. The testing was to be in a high-fidelity simulation, against a number of stressing conditions, in order to discern the most flexible approaches.

In this paper, we examine approaches in the areas of ascent/abort guidance, entry guidance, and flight control. We summarize an initial phase of testing performed to examine the various methods and describe these methods. Some lessons were learned from the initial phase of testing. Some of the algorithms performed well, but for the most part the methods were not ready to address all the RLV needs. We planned a second phase of testing to more completely examine the performance of the algorithms versus the safety/cost requirements. This paper includes a description of the test cases for the second phase of testing. This paper also describes an automated method of scoring, for evaluating the results of tests, that results in a significant reduction of effort. We include results of the second phase of testing at the end of the paper.

\section{First Phase of Testing}

An original goal in this effort was to include as many approaches as possible within the resources of the effort, with an eye toward not missing what may be the best approach. The methods had to be openly available (not proprietary), and available with a relatively small budget. This led to an emphasis on university grants and in-house efforts. Some of

\footnotetext{
'Aerospace Engineer, NASA Marshall Space Flight Center/TD54, Huntsville, AL 35812.

2 Senior Engineer, Sverdrup Technology, Inc., MSFC Group, 6703 Odysscy Drive. Suite 303, Huntsvillc, AL 35806
} 
the methods' development was funded separately but was furnished by the authors for testing in this environment.

A test series was conducted in September 2000. No ascent/abort guidance algorithms were available for this first phase of testing. Four entry guidance methods were tested, as were five control approaches. The test environment was the high-fidelity X-33 Marshall Aerospace Vehicle Representation in C (MAVERIC) simulation (Ref. 2). The X-33 was planned to fly a number of sub-orbital test flights, so these tests encompassed primarily ascent followed immediately by entry on sub-orbital trajectories. For the entry guidance methods, additional tests were run for entry from various orbits, with differing crossrange requirements and heat constraints.

Tests included different nominal missions, engine-out aborts, dispersion Monte Carlo runs for both nominal missions and aborts, and significant engine over and under performance. Failures and mis-modeling not associated with the propulsion system were not explicitly considered for this Phase 1 testing. Algorithm size, speed of execution, memory, complexity/effort required, and performance against a variety of criteria were all compared.

Of all the methods tested, the linear quadratic regulator entry guidance was the only one that performed quite well. In all cases, it became clear that more work was necessary to develop the algorithms to their full potential, so that they would successfully attack the various test cases. This led to the definition of a second set of tests, as described below, and to more work on the algorithms, as described in the references.

\section{Methods to be Examined}

The work in this paper continues from work first described in Reference 2. The methods under examination are described in that paper, but are listed below for reference, along with the current status.

\section{Ascent guidance}

- In the first method, judicious approximations are made to reduce the order and complexity of the state/costate system, and multiple shooting is used. It reoptimizes the ascent trajectory every guidance cycle from liftoff to engine burnout (Ref. 3). Ascent and abort are both covered. Results for Phase 2 testing are included in this paper.

- Neighboring optimal control (NASA Langley Research Center). This method has not been available for testing yet.

- Trajectory-following guidance (NASA MSFC). This method was not pursued due to a lack of available manpower.

- There are two more approaches under development that have not been tested in this environment yet. One is being developed by Iowa State University (Ref. 4) under subcontract to Ohio University on a NASA $2^{\text {nd }}$ Generation RLV contract, and the other is being developed by Guided Systems Technology Inc. (Ref. 5) 
under a Phase 2 Small Business Innovative Research (SBIR) contract with the Air Force Research Lab. We are hoping to include these two approaches in testing.

\section{Entry guidance}

- Linear quadratic regulator. This method (Ref. 6) was not listed in Ref. 2 but has performed very well in test. Results for Phase 2 testing are included in this paper.

- Predictor-corrector. This method (Ref. 7) has been adapted to provide a trajectory for another entry guidance method to follow. It is functioning as a trajectory generator rather than as a guidance scheme. Results for Phase 2 testing are included in this paper.

- A trajectory design method that uses quasi-equilibrium glide, combined with a predictor-corrector method, to choose parameters for entry. (Ref. 8). Guidance flies these profiles. The guidance method was also tested during Phase 2 testing.

- An entry trajectory design and guidance procedure based on extension of the Shuttle trajectory design methods to three dimensions. The planning algorithm generates reference drag acceleration and lateral acceleration profiles, along with the reference state and bank angle profiles. A feedback linearization control is used to track the reference profiles (Ref. 9). This method is not available for testing as of this writing.

Flight control

- Sliding mode controller (Ref. 10). This controller showed some promise in phase 1 testing. This work has been combined with controller design by trajectory linearization (Ref 14) and reconfigurable control allocation (Ref 13). Results for Phase 2 testing are included in this paper.

- Fault tolerant nonlinear adaptive controller using neural nets (Ref. 11). This controller showed some promise in phase 1 testing. Results for Phase 2 testing are not available of this writing.

- Dynamic inversion (Ref. 12). Phase 1 testing was for ascent only, as the control method was not ready for entry flight. The algorithm had trouble for ascent primarily due to some cases where a subroutine bombed and also due to not following the guidance overall throttle command. The investigator has had insufficient time available to pursue this work during the current testing period.

- Robust inversion and data compression in control allocation. This work has been updated to provide reconfigurable control allocation (Ref. 13). It has been combined with the sliding mode controller work (Ref. 10) and trajectory linearization control work (Ref 14) in a single algorithm architecture. Test results are included in this paper.

- Linear parametrically varying controller. This control approach was nowhere close to being ready for testing when the first phase of testing occurred, and was dropped from consideration.

- Controller design by trajectory linearization (Ref. 14). This method showed some promise in Phase 1 testing and was tested during Phase 2 as part of an overall 
algorithm architecture that includes the sliding mode controller (Ref 10) and reconfigurable control allocation (Ref 13 ).

\section{Test Cases and Test Criteria}

For the second phase of tests, we included many of the first set of tests again, since the methods did not in most cases perform satisfactorily. We also added tests for various failure and mis-modeling cases that seemed appropriate. The test environment was a newer version of MAVERIC that models the X-33 vehicle in more detail and automates some of the test processes required. A list of the test cases follows in Table 1. Table 2 shows the motivation for each set of tests. Table 3 lists the criteria compared for each of the various tests. The actual parameters scored, weights, and limit values vary between test cases and are too extensive to list here. See Ref. 15 for a complete description.

\section{Table 1. Phase 2 Test Series}

DOF: Degrees of Freedom; MCD: Monte Carlo Dispersions; PPO: Power Pack Out (Engine Failure, time of failure indicated); AGC is a vehicle with X-33 characteristics with specific impulse doubled so it can reach orbit; Michael (nominal) and Ibex (low energy) are X-33 landing sites; Mich 10al and 10dl are planned X-33 trajectories; MECO: main engine cutoff; alpha is angle of attack; $Q$ is dynamic pressure; $Q$-alpha is dynamic pressure times angle of attack; seed indicates whether a new random number was used to start certain test cases; season is which part of the year is used for environmental dispersions. All environments are for the month of April unless noted. EAFB is Edwards AFB. GRAM is Global Reference Atmosphere Model. ISS is International Space Station; LEO is low Earth orbit. TVC is thrust vector control.

\section{ASCENT GUIDANCE TEST SERIES}

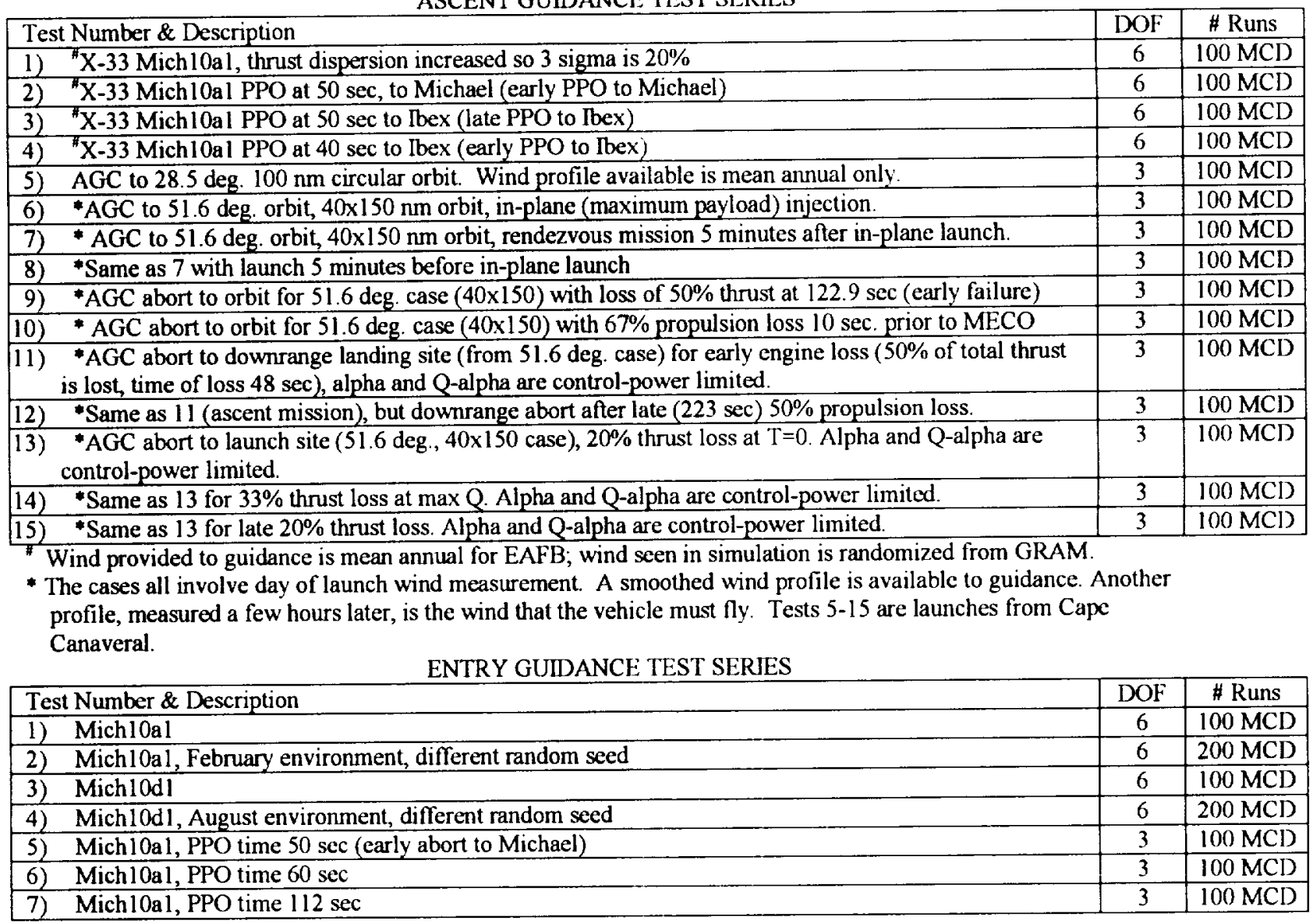


8) Mich10al, PPO time 40 sec (early to lbex), different random seed

9) Michlodl, PPO time $38 \mathrm{sec}$ (early to lbex), different random seed

10) Mich10al, +4 sigma thrust dispersion from ascent

11) Mich10al, +6 sigma thrust dispersion from ascent

12) Mich10a1, -12 sigma thrust dispersion from ascent

13) 51.6 deg. ISS orbit entry, low crossrange, high peak heat rate limit, input profile to guidance is from this trajectory's design.

14) 51.6 deg. ISS orbit entry, high right crossrange, high peak heat rate limit, input profile from 13.

15) $51.6 \mathrm{deg}$. ISS orbit entry, high left crossrange, high peak heat rate limit, input profile from 13.

16) $51.6 \mathrm{deg}$. ISS orbit entry, low crossrange, low peak heat rate limit, input profile from this trajectory's design.

17) $51.6 \mathrm{deg}$. ISS orbit entry, high right crossrange, low peak heat rate limit, input profile from 16

18) 51.6 deg. ISS orbit entry, high left crossrange, low peak heat rate limit, input profile from 16

19) 28.5 deg. LEO orbit entry, low crossrange, low peak heat rate limit, input profile from 16.

20) 28.5 deg. LEO orbit entry, high right crossrange, low peak heat rate limit, input profile from 16

21) 28.5 deg. LEO orbit entry, high left crossrange, low peak heat rate limit, input profile from 16.

22) Mich10al, aerosurface failure result: angle of attack limited to 5 deg. less that nominal entry value.

23) Michl0al, aerosurface failure result: angle of attack and bank rates limited to $2 \mathrm{deg}$./sec. maximum.

24) Michlodl, aerosurface failure: angle of attack limited to 5 deg. less that nominal entry value.

25) MichlOdl, aerosurface failure: angle of attack limited to $5 \mathrm{deg}$. less that nominal entry value, and angle of attack and bank rates limited to $2 \mathrm{deg} . / \mathrm{sec}$. maximum

26) Mich10al, unknown to guidance, first flight aerodynamics mis-modeling: aerodynamic lift coef. $20 \%$ less than vehicle database model.

27) Michl0al, unknown to guidance, first flight aerodynamics mis-modeling: aerodynamic lift coef. $20 \%$ more than vehicle database model.

28) Mich10al, unknown to guidance, first flight aerodynamics mis-modeling: aerodynamic lift coef. $20 \%$ less and aerodynamic drag is $20 \%$ more than vehicle database model.

FLIGHT CONTROL TEST SERIES

\begin{tabular}{|c|c|c|}
\hline Test Number \& Description & DOF & \# Runs \\
\hline 1) Mich10al & 6 & 1 \\
\hline 2) Mich10dl & 6 & 1 \\
\hline 3) Michl0a 1, PPO time 36 sec (early to Ibex) & 6 & 1 \\
\hline 4) Mich10d1, PPO time $50 \mathrm{sec}$ (early to Michael) & 6 & 1 \\
\hline 5) TVC command bias on Engine A: Roll/Pitch TVC commands $+0.5 \%$ & 6 & 1 \\
\hline 6) TVC command bias on Engine B: Roll/Pitch TVC commands $-1.0 \%$ & 6 & 1 \\
\hline 7) TVC command bias on Yaw: TVC commands $+1.0 \%$ & 6 & 1 \\
\hline 8) +3 sigma $\mathrm{Fz}, \mathrm{My}$ on Engine $\mathrm{A},-3$ sigma $\mathrm{Fz}, \mathrm{My}$ on Engine $\mathrm{B}$ & 6 & 1 \\
\hline 9) Right inboard elevon fails to $+10 \mathrm{deg}$. 50 seconds into flight for 30 seconds. & 6 & 1 \\
\hline 10) Left outboard elevon fails to -15 deg. 275 seconds into flight for 45 seconds. & 6 & 1 \\
\hline 11) Right flap fails to +2 deg. 150 seconds into flight for 20 seconds. & 6 & 1 \\
\hline 12) Right flap fails to +2 deg. 300 seconds into flight for 20 seconds. & 6 & 1 \\
\hline 13) Right rudder fails to -30 deg. 30 seconds into flight for remainder of flight. & 6 & 1 \\
\hline 14) Left inboard elevon fails to null 35 seconds into flight for remainder of flight. & 6 & 1 \\
\hline 15) Right outboard elevon fails to null 250 seconds into flight for remainder of flight. & 6 & 1 \\
\hline 16) Right flap fails to null at 20 seconds into flight for remainder of flight. & 6 & 1 \\
\hline 17) Left flap fails to null at 215 seconds into flight for remainder of flight. & 6 & 1 \\
\hline 18) Right outboard elevon jams 58 seconds into night for remainder of flight. & 6 & 1 \\
\hline 19) Left inboard elevon jams 208 seconds into flight for remainder of flight. & 6 & 1 \\
\hline 20) Right flap jams 170 seconds into flight for remainder of flight. & 6 & 1 \\
\hline 21) Left flap jams 280 seconds into flight for remainder of flight. & 6 & 1 \\
\hline 22) Fail $1 \& 10$ at MECO (loss of pure yaw capability) & 6 & 1 \\
\hline 23) Fail $5 \& 9$ at MECO (loss of pure yaw capability) & 6 & 1 \\
\hline 24) Fail 4 at MECO (loss of yawroll capability) & 6 & 1 \\
\hline 25) Fail 8 at MECO (loss of yawroll capability) & 6 & 1 \\
\hline 26$)+3$ sigma $\mathrm{Cm},+3$ sigma $\mathrm{Ca},+3$ sigma $\mathrm{CN}$ & 6 & 1 \\
\hline 27) -4 sigma $\mathrm{Cm},-4$ sigma $\mathrm{Ca},-4$ sigma $\mathrm{CN}$ & 6 & 1 \\
\hline 28) -3 sigma $C Y,-3$ sigma $C l,-3$ sigma $C n$ & 6 & 1 \\
\hline 29) -4 sigma rotary derivative increments. & 6 & 1 \\
\hline 30) -3 sigma $\mathrm{Cm}, \mathrm{Ca}, \mathrm{CN}$ (body flap), +3 sigma $\mathrm{CY}, \mathrm{Cl}, \mathrm{Cn}$ (body flap) & 6 & 1 \\
\hline
\end{tabular}


31) +3 sigma CY, Cl, Cn (elevons)

32) +4 sigma jet effect increments on control surface effectiveness

33) +3 sigma adverse yaw moment increments on elevons \& body flaps

34) $2 \mathrm{~Hz}, 10 \%$ nominal pitch signal magnitude, $30 \mathrm{deg}$. phase angle signal added to nominal navigation output to account for vibrational mode mis-modeling (simplified test of mis-modeling)

35) $2 \mathrm{~Hz}, 10 \%$ nominal yaw/roll signal magnitude, $30 \mathrm{deg}$. phase angle signal added to nominal navigation output

36) $2 \mathrm{~Hz}, 20 \%$ nominal pitch signal magnitude, $30 \mathrm{deg}$. phase angle signal added to nominal navigation output

37) $2 \mathrm{~Hz}, 20 \%$ nominal yaw/roll signal magnitude, $30 \mathrm{deg}$. phase angle signal added to nominal navigation output

38) $2 \mathrm{~Hz}, 10 \%$ nominal pitch signal magnitude, 45 deg. phase angle signal added to nominal navigation output

39) $2 \mathrm{~Hz}, 10 \%$ nominal yaw/roll signal magnitude, 45 deg. phase angle signal added to nominal navigation output

40) $4 \mathrm{~Hz}, 5 \%$ nominal pitch signal magnitude, $0 \mathrm{deg}$. phase angle signal added to nominal navigation output

41) $4 \mathrm{~Hz}, 5 \%$ nominal yaw/roll signal magnitude, 0 deg. phase angle signal added to nominal navigation output

42) $10 \mathrm{~Hz}, 10 \%$ nominal pitch signal magnitude, 60 deg. phase angle signal added to nominal navigation output

43) $10 \mathrm{~Hz}, 10 \%$ nominal yaw/roll signal magnitude, $60 \mathrm{deg}$. phase angle signal added to nominal navigation output

44) Mich 10al

45) Mich10a 1, February environment, different random seed

46) Michlodl

47) Mich10d l, August environment, different random seed

48) Michl0al, PPO time $60 \mathrm{sec}$

49) Michl0al, PPO time $112 \mathrm{sec}$

50) Mich10al, PPO time $40 \mathrm{sec}$, different random seed

51) Michl0d1, PPO time $38 \mathrm{sec}$, different random soed

\begin{tabular}{|c|c|}
\hline 6 & 1 \\
\hline 6 & 1 \\
\hline 6 & 1 \\
\hline 6 & 1 \\
\hline 6 & 1 \\
\hline 6 & 1 \\
\hline 6 & 1 \\
\hline 6 & 1 \\
\hline 6 & 1 \\
\hline 6 & 1 \\
\hline 6 & 1 \\
\hline 6 & 1 \\
\hline 6 & 1 \\
\hline 6 & $100 \mathrm{MCD}$ \\
\hline 6 & $200 \mathrm{MCD}$ \\
\hline 6 & $100 \mathrm{MCD}$ \\
\hline 6 & $200 \mathrm{MCD}$ \\
\hline 6 & $100 \mathrm{MCD}$ \\
\hline 6 & $100 \mathrm{MCD}$ \\
\hline 6 & $200 \mathrm{MCD}$ \\
\hline 6 & $200 \mathrm{MCD}$ \\
\hline
\end{tabular}

Table 2. Motivation for the Tests

\begin{tabular}{|l|l|}
\hline Tests & Motivation \\
\hline $1-4$ & Ascent Guidance \\
\hline $5-15$ & $\begin{array}{l}\text { X-33 missions with dispersions and engine failures. Launch from EAFB. } \\
\text { Guidance robustness and adaptability. }\end{array}$ \\
\hline 5 & $\begin{array}{l}\text { AGC vehicle launched from CCAFS/KSC. } \\
\text { when a measured wind is not available to guidance. }\end{array}$ \\
\hline $6-8$ & 51.6 deg. orbit; measure performance and adaptability to different orbits. \\
\hline $9-15$ & $\begin{array}{l}\text { Abort to orbit, abort from orbit to landing site, abort to launch site. Ability } \\
\text { of guidance/trajectory design to adapt to a range of failure cases. }\end{array}$ \\
\hline $1-4$ & Entry Guidance \\
\hline $5-9$ & $\begin{array}{l}\text { Engine failures; robustness to large off-energy cases and alternate landing } \\
\text { sites }\end{array}$ \\
\hline $10-12$ & $\begin{array}{l}\text { Large thrust dispersions; ability to maximize probability of successful } \\
\text { landing }\end{array}$ \\
\hline $13-21$ & $\begin{array}{l}\text { Entry from orbit; ability to adapt to different heating requirements and } \\
\text { crossrange requirements with dispersions. }\end{array}$ \\
\hline
\end{tabular}




\begin{tabular}{|l|l|}
\hline $22-25$ & Effects from failures causing a change in maneuverability \\
\hline $26-28$ & Mis-modeling of aerodynamics on first flight \\
\hline & Control System \\
\hline $1-2$ & Nominal X-33 missions; robustness to differing missions \\
\hline $3-4$ & Engine failures; robustness to different thrust levels \\
\hline $5-8$ & Thrust Vector Control Failure \\
\hline $9-21$ & Aerosurface failure \\
\hline $22-29$ & Modeling erroes \\
\hline $30-36$ & Mis-modeling of vibrational modes \\
\hline $37-44$ & Nominal X-33 missions with dispersions \\
\hline
\end{tabular}




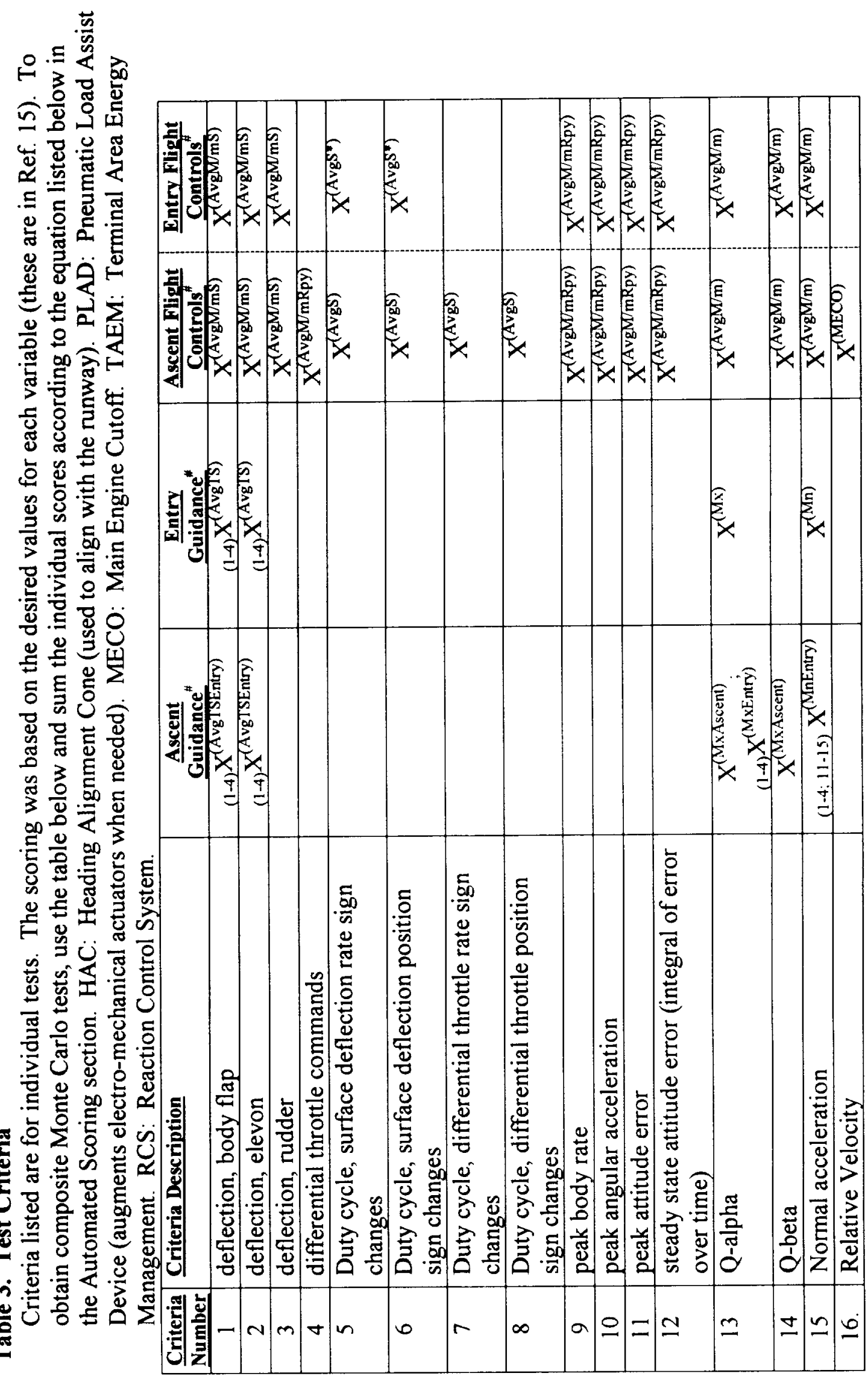




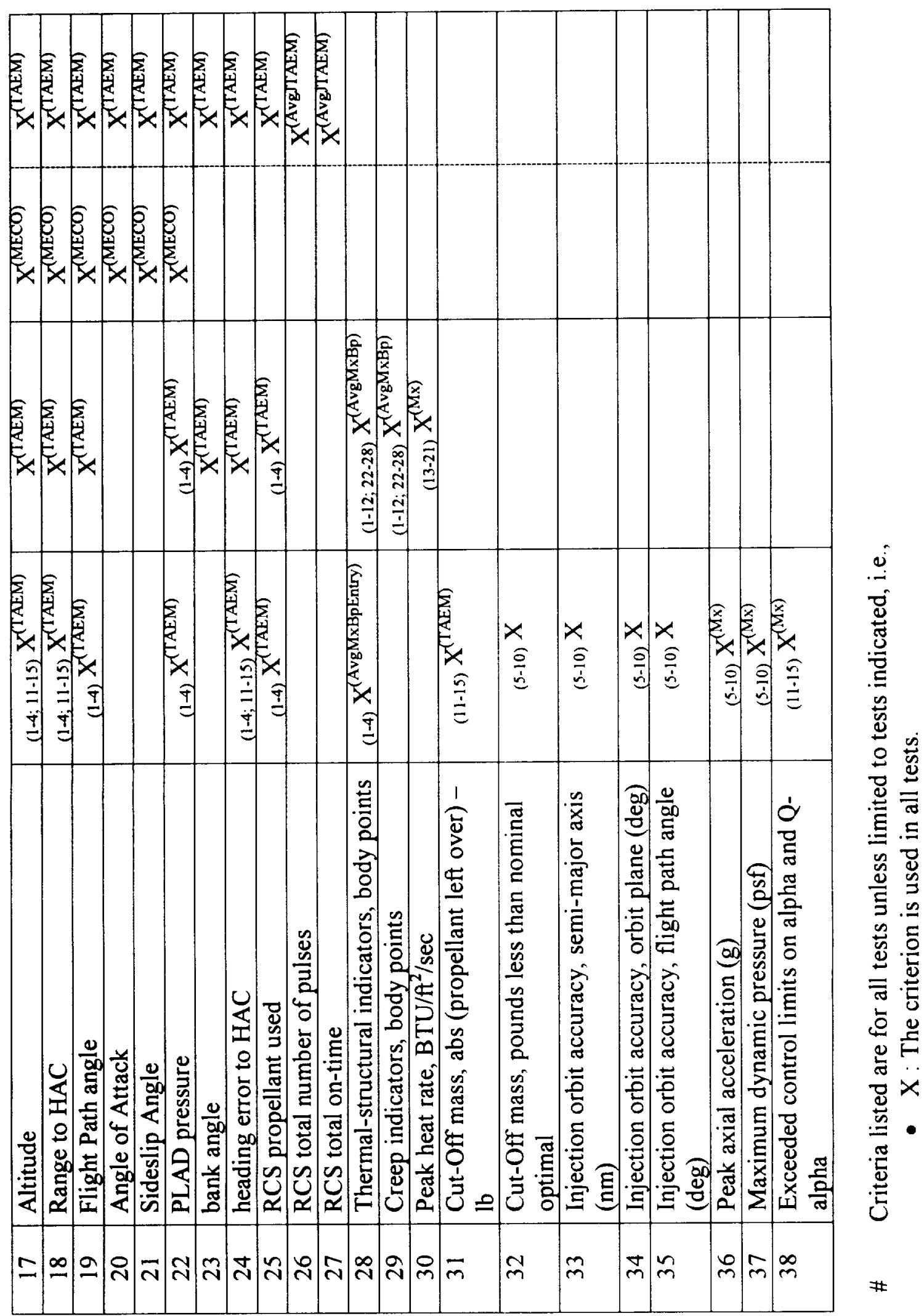




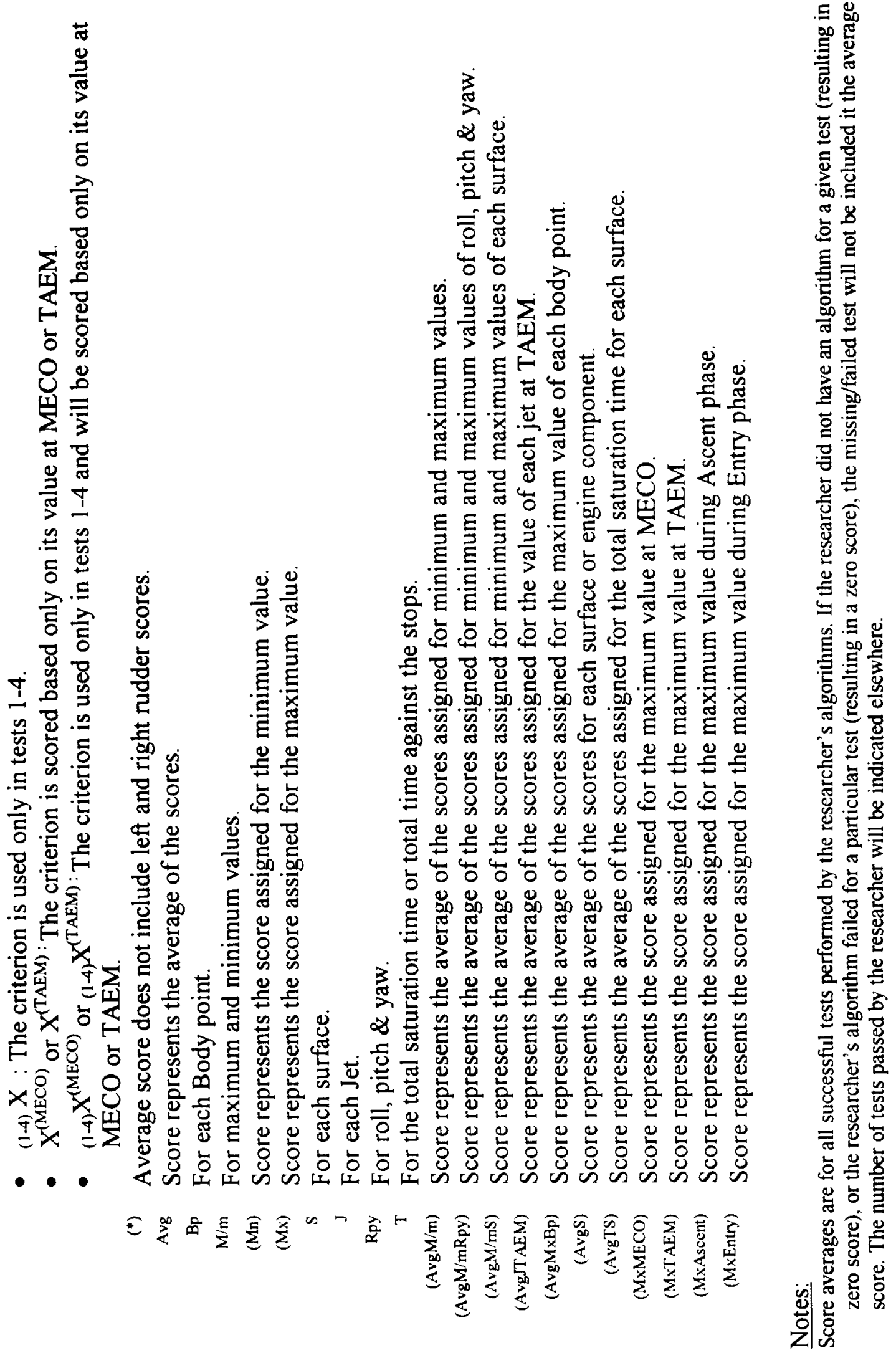




\section{Automated Scoring}

The Phase 1 test evaluation involved a number of guidance and control experts reviewing the results (both graphical and numerical) and determining how well the method flew the vehicle. This approach worked, but had two drawbacks: 1) It requires a large amount of engineer time for evaluation of many parameters on many tests for multiple algorithms, and 2) the final evaluation has some subjectivity in it (and could potentially result in uneven evaluation). There was a benefit to this method, however. In evaluating the methods, it became clear to the evaluators what parameters were important to them and what values of these parameters were acceptable. As a result, we were able to automate the scoring process for the Phase 2 tests.

Tests are numerically scored, and then each test is weighted, with the scores added, so that the algorithms have a final numerical score. Normalization results in a perfect score being given a value of 1.0 . For each parameter to be tested, there is a weight, and these multiply that parameter's score and add into the total. Single tests (not Monte Carlo dispersions) are scored as in this example:

Normal acceleration: $0-3.5 \mathrm{~g}, 1.0-2.5 \mathrm{~g}$ means the score is 1.0 for normal acceleration magnitudes below $2.5,0.0$ for values above 3.5 , and linearly varying in between the two limit values. The parameter score is multiplied by the weight for that parameter (normal acceleration) and added into the total score for that test.

For Monte Carlo dispersion tests, the overall score is the average of the individual scores. A final criteria used for the entry guidance and flight control tests regards accuracy in reaching the TAEM targets. If the range, altitude, and heading angles are not sufficiently controlled in order to be able to land successfully, the test was considered a failure (score of 0 ) even if other criteria were met. Typical values used for the required accuracy at hitting the TAEM condition were $7 \mathrm{~nm}, 7000 \mathrm{ft}$, and $10 \mathrm{deg}$, respectively. If more than $10 \%$ of Monte Carlo cases fail to meet these TAEM conditions, then the entire Monte Carlo run is given a score of 0.0 .

The detailed scoring parameters and weights appear in Reference 15.

\section{Results}

Results of the tests are shown in the following figures. A couple of examples from early tests are below. The baseline $\mathrm{X}-33$ guidance and control $(\mathrm{G} \& \mathrm{C})$ will be used for comparison for tests where the baseline $\mathrm{G} \& \mathrm{C}$ is able to fly the vehicle. (The baseline G\&C consists of PID control, open-loop ascent guidance in the atmosphere, linear tangent steering vacuum closed-loop guidance, and Shuttle-derived entry guidance). Results from testing the rest of the algorithms will appear in the final paper. Complete test results are in Ref. 15.

Figure 1 shows the performance for each test case. A score of 0.0 may mean the algorithm failed the test or that the algorithm is not ready to perform that test case yet. 
We expect the final paper will include more complete test results for each algorithm, more algorithms in test, and ascent guidance and control system tests as well as entry guidance tests.

The criteria graph (Fig. 2) shows the performance on the various criteria from each algorithm. The criteria are in Table 3. The performance is shown only for those tests that did not fail (did not score a zero on the test cases graph). This way, the reader will see information on how the method performed for the various criteria. The number of successful tests for each algorithm can be determined from the test cases graph.
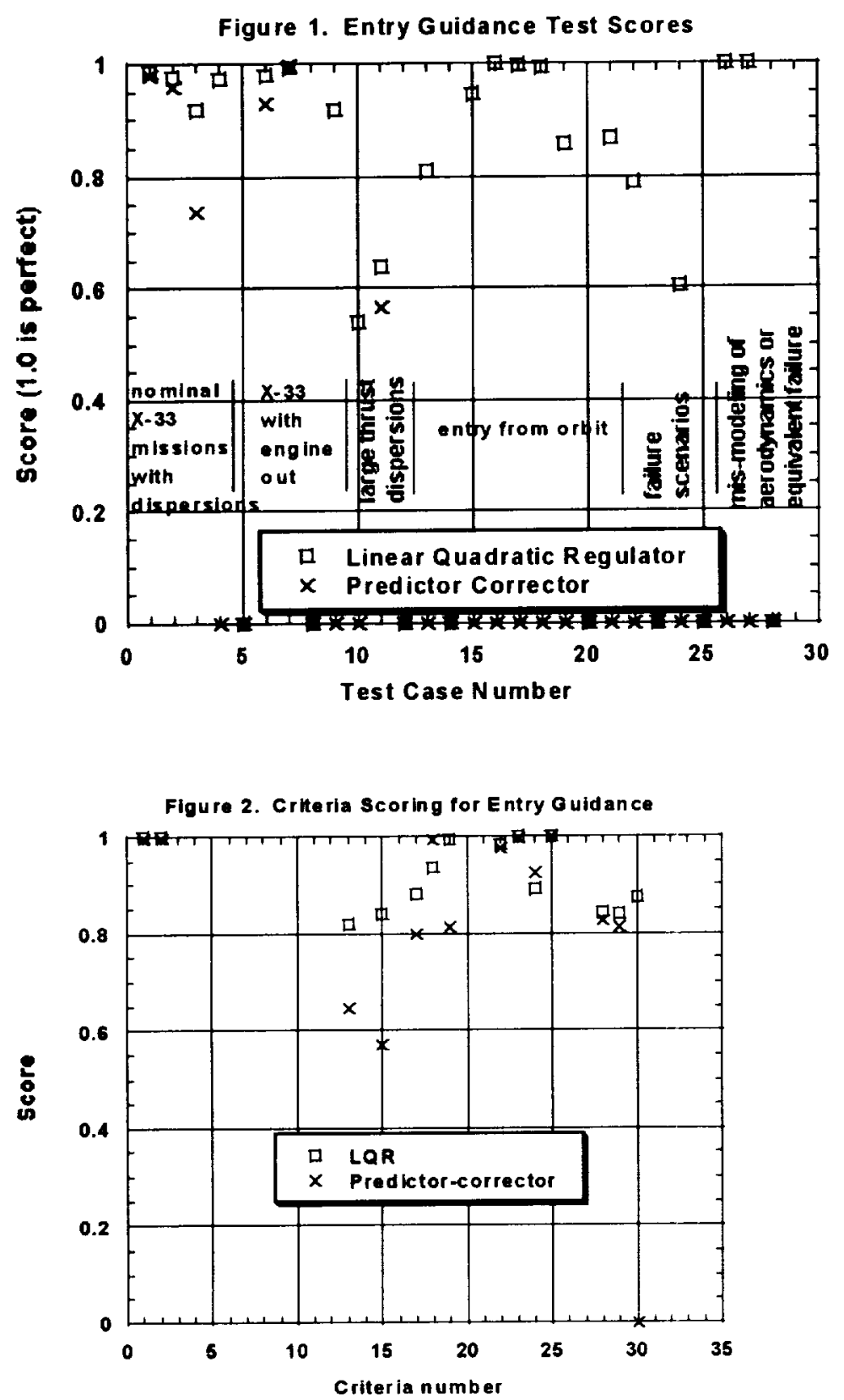


\section{Summary}

This paper gives the results of testing of a number of advanced guidance and control methods for application to future reusable launch vehicles. The methods were tested in high-fidelity simulation to determine their performance with respect to nominal missions, engine-out situations, dispersions, various failures, and vehicle mis-modeling. We expect that the best of these methods will yield improved safety and reduced cost for future reusable launch vehicles. Summarize any relevant results here. A final version of this paper will contain complete test results, and will be submitted for publication. Follow-on work is planned to choose between the various guidance and control options and to integrate them into a single G\&C architecture that meets the safety and cost needs of the $2^{\text {nd }}$ Generation RLV Program. More complete testing will be conducted on the integrated architecture.

\section{References}

1. Hanson, J., "A Plan for Advanced Guidance and Control Technology for $2^{\text {nd }}$ Generation Reusable Launch Vehicles," 2002 AIAA Guidance, Navigation, and Control Conference, Monterey, CA, Aug 2002.

2. Hanson, J., "Advanced Guidance and Control Project for Reusable Launch Vehicles," AIAA-2000-3957, Proceedings of the 2000 AIAA Guidance, Navigation, and Control Conference.

3. Dukeman, G.A., "Atmospheric Ascent Guidance for Rocket-Powered Launch Vehicles," paper 2002-4559, AIAA Guidance, Navigation, and Control Conference, Monterey, CA, Aug 2002.

4. Sun, H., and Lu, P., "Closed-loop Endoatmospheric Ascent Guidance," paper 20024558, AIAA Guidance, Navigation, and Control Conference, Monterey, CA, Aug 2002.

5. Calise, A., and Brandt, N., "Generation of Launch Vehicle Abort Trajectories using a Hybrid Optimization Method," paper 2002-4560, AlAA Guidance, Navigation, and Control Conference, Monterey, CA, Aug 2002.

6. Dukeman, G.A., "Profile-Following Entry Guidance Using Linear Quadratic Regulator Theory," paper 2002-4457, AIAA Guidance, Navigation, and Control Conference, Monterey, CA, Aug 2002.

7. Zimmerman, C., Dukeman, G., and Hanson, J., "An Automated Method to Compute Orbital Re-entry Trajectories with Heating Constraints,” paper 2002-4454, AIAA Guidance, Navigation, and Control Conference, Monterey, CA, Aug 2002

8. Shen, Z., and Lu, P., "On-Board Generation of Three-Dimensional Constrained Entry Trajectories," paper 2002-4455, AIAA Guidance, Navigation, and Control Conference, Monterey, CA, Aug 2002.

9. Chen, D.T., Saraf, A., Leavitt, J.A., and Mease, K.D., "Performance of Evolved Acceleration Guidance Logic for Entry (EAGLE)," paper 2002-4456, AIAA Guidance, Navigation, and Control Conference, Monterey, CA, Aug 2002.

10. Shtessel, Y., Zhu, J., and Daniels, D., "Reusable Launch Vehicle Attitude Control using a Time-Varying Sliding Mode Control Technique," paper 2002-4779, AIAA Guidance, Navigation, and Control Conference, Monterey, CA, Aug 2002. 
11. Johnson, E., Calise, A., and Corban, J.E., "A Six Degree-of-Freedom Adaptive Flight Control Architecture for Trajectory Following," AIAA-2002-4776, AIAA Guidance, Navigation, and Control Conference, Monterey, CA, Aug 2002.

12. Doman, D., Leggett, D., Ngo, A., Saliers, M., and Pachter, M., "Development of a Hybrid Direct-Indirect Adaptive Control System for the X-33, AIAA-2000-4156, AIAA Guidance, Navigation, and Control Conference, Denver, CO, Aug 14-17, 2000.

13. Hodel, A. S., and Callahan, R., "Autonomous Reconfigurable Control Allocation (ARCA) for Reusable Launch Vehicles," paper 2002-4777, AIAA Guidance, Navigation, and Control Conference, Monterey, CA, Aug 2002.

14. Zhu, J., Lawrence, D., Fisher, J., Shtessel, Y., Hodel, A.S., and Lu, P., "Direct Fault Tolerant RLV Attitude Control-A Singular Perturbation Approach," paper 20024778, AIAA Guidance, Navigation, and Control Conference, Monterey, CA, Aug 2002.

15. Results of Phase 2 of Advanced Guidance and Control Project Testing, NASA Technical Memorandum, to be published. 